\title{
Bitcoin Alternatif Yatırım Aracı ya da Hedge Enstrümanı Olarak Düşünülebilir mi?
}

\section{Can It Be Considered As Bitcoin Alternative Investment Instrument or Hedge Instrument?}

Serdar Kuzu, ${ }^{a^{*}}$ İsmail Erkan Çelik ${ }^{\mathrm{b}}$

${ }^{a}$ Dr. Öğr. Ü. İstanbul Üniversitesi Cerrahpaşa, Muhasebe ve Vergi Bölümü, İstanbul/Türkiye. ORCID: 0000-0001-8178-8749

${ }^{\text {b }}$ Dr. Öğr. Ü. Doğuş Üniversitesi İktisadi ve İdari Bilimler Fakültesi, İstanbul/Türkiye. ORCID: 0000-0002-2274-0750

\section{MAKALE BİLGISI}

\section{Makale Geçmişi}

Başvuru tarihi: 21 Aralık 2019

Düzeltme tarihi: 10 Şubat 2020

Kabul tarihi: 25 Şubat 2020

\author{
Anahtar Kelimeler: \\ Bitcoin \\ Kripto Paralar \\ Borsa
}

ARDL Sinır Testi Modeli

\section{ARTICLE INFO}

\section{Article history:}

Received 21 December 2019

Received in revised form 10 February 2020

Accepted 25 February 2020

\author{
Keywords: \\ Bitcoin, \\ Cryptocurrency, \\ Stock Exchange \\ ARDL Boundary Test Method
}

ÖZ

\begin{abstract}
Finansal piyasaların ilgi noktasını olușturan kripto para birimlerinden bitcoin'in para birimi olarak yayılması ve kullanılmasından sonra herkesin aklında, bitcoin'in bir yatırım aracı olarak ya da hedge enstrümanı olarak değerlendirilip değerlendirilemeyeceği sorusu yer almaya başlamıştır. Çalışmada kripto para birimlerinden en çok işlem hacmine sahip olan bitcoin'in alternatif yatırım araçları arasında uzun dönemli ilişkilerini ortaya koymak için istatistiki analiz yapılmış ve bununla ilgili bulgular tartışılmıştır. Birçok kripto para olmasına karşın Bitcoin'in her açısından önde gelmesi nedeniyle, bitcoin ile alternatif yatırım araçları arasında bir eş bütünleşmenin olup olmadığı ARDL testi ile ortaya koyulmaya çalışılmıştır. Çalışmada Bitcoin ile alternatif yatırım araçları arasında geniş kapsamda ele alan salt bir çalışma görülmediğinden dolayı bu çalışmanın yapılmasına karar verilmiştir.
\end{abstract}

\section{A B S T R A C T}

After the spread and use of bitcoin as one of the cryptocurrencies that constitute the point of interest of the financial markets, the question of whether or not bitcoin can be evaluated as an investment tool or hedge instrument has begun to be raised. In the study, statistical analysis was made to reveal the long-term relationship between alternative investment instruments of bitcoin, which has the highest transaction volume from cryptocurrencies, and the findings related to this were discussed. Although there are many cryptocurrencies, Bitcoin is prominent in every respect, it is tried to be determined whether there is a co-integration between bitcoin and alternative investment instruments by using ARDL test.

\section{Giriş}

Günümüzde bilgi iletişim teknolojisinde yaşanan gelişimeler piyasalarda finansal hizmetlere yönelik yenilikleri de beraberinde getirmiştir. Klasik finansal anlayış ve araçları popülaritesini yitirmeye başlarken elektronik para, yenilikçi şifreleme teknolojisi ve türev ürünler gibi araçlar piyasada yerini almaya başlamıştır. $\mathrm{Bu}$ süreçte kripto paralar içerisinde en popüler olan bitcoin gibi yenilikçi finansal hizmetler birçok yatırımcının odak noktasını oluşturmaya başlamıştır. Kripto para kavramının temelinde bulunan ve geleneksel yöntemlerden farklılaşmış veri tabanı algoritmalarının, finansal piyasalarda yer almaya başladığ gözlemlenmektedir. Özellikle bankacılık sektörü gün geçtikçe bu tür algoritmaları sistemlerine entegre edebilmek için çalışmalar yapmaya devam etmektedirler. Bitcoin'in, bankaların sıklıkla karşılaştıkları birçok sorun için bir çözüm sunduğu görülmektedir. Özellikle hesaplamalardaki şeffaflık, dijital kontratlar ve geri dönüşümsüz işlemler ile Bitcoin, güven ve mutabakat sağlama amacı ile kullanılabilmektedir. Bitcoin işlemleri halka açık ve şeffaf olmasına rağmen, değiştirilmediği takdirde bu işlemleri

\footnotetext{
* Sorumlu yazar/Corresponding author.

e-posta: serdar.kuzu@istanbul.edu.tr
} 
yapan kişilerin kimlikleri gizlidir. Bu da kişilere ve şirketlere şeffaf bir çalışma ortamı hazırlar. Bu sayede kripto paralar özellikle gizlilik kaygısı olan kullanıcılar için popüler bir ödeme aracı haline gelmiştir (Ateş, 2016, s. 358).

Kripto paraların son on yılda göstermiş olduğu performans ve kullanıcı sayılarındaki artışı göz önüne alındığında bu alanda yaşanacak gelişmelerin hız kazanacağı aşikârdır. Bu yükselişin hem dijital para ekosisteminde hem de teknolojik yeniliklerin gelişmesinde etkili olacağı düşünülmektedir. 2008 yılındaki küresel kriz sonrası finansal kuruluşlara ve devletlerin mali yapılarına karşı güvenin yitirilmesi, kripto para sistemlerinin popülerliğinin artmasına neden olmuştur. Siyasi müdahaleler, savaş riskleri ve Merkez Bankalarının diğer bankaları kurtarma politikalarının bireylere verdiği zararlardan kaçınmak için bu sistemler önemli bir alternatif olma yolunda hızla ilerlemektedir (Öz, 2011).

Yaşanan gelişmeler 1şı̆̆ında 2008 yılında Satoshi Nakamoto tarafidan yayınlanan "Bitcoin: Eșten Eșe Nakit Ödeme Sistemi" adlı makale finansal piyasalara yeni bir boyut getirmiş olup, bunun sonucunda 2008 yılında Satoshi Nakamoto tarafindan herhangi bir otoriteye bağlı olmadan oluşturulmuş sanal para birimi olan Bitcoin ortaya çıkmıştır (Nakamoto, 2008).

\section{Kripto Para Kavramı}

Kripto para kavramı, son yıllarda ortaya çıkan bir kavram olup en genel manada sayısal para veya sayısal emtia olarak tanımlanmaktadır. Kripto paraların en popüleri olan Bitcoin 2009 yılında hayatımıza girmiş ve hiçbir ülke veya kuruluşa bağlı olmaksızın tamamen bağımsız olarak bireylerin kendi kişisel bilgisayarlarını kullanarak oluşturulan sanal değerlerin takas edilmesi temeline dayanan bir para birimi olarak ortaya çıkmıştır. Kripto paralar geleneksel Fiat paralar (Dolar, Euro, TL vb.) gibi belirli bir merkez bankası, ülke veya kuruluş tarafindan basılmamakta ve kontrol edilmemektedir (Parasız, 2000). Bitcoin'in sağladığı teknoloji, alıcı ve satıcı arasında doğrudan ilişki kuran ve 3.partilere olarak bağımlılığı ortadan kaldırırken karşılaştırılabilir alternatiflere göre oldukça düșük bir maliyette işlemlerin gerçekleştiği ve zamandan bağımsız bir şekilde dünyanın her yerine servet transferine olanak sağlayan bir sistemdir.

Kripto paranın elektronik para olarak ifade edilmesinin sebebi parasal bir değerin sayısal olarak saklanmasından kaynaklanmaktadır. Kripto paraları elektronik paradan ziyade elektronik bir emtia şeklinde tanımlamak daha doğru olacaktır. Çünkü tıpkı emtialar da olduğu gibi kripto paraların da arzı sınırlıdır. Arzın sınırlı olması, finansal piyasalar gerçeği olarak karşımıza çıkan dalgalı bir fiyatlanma sonucunu doğurmaktadır. Çünkü kur değişkenliği, piyasa dinamikleri ve arz ile doğrudan ilişkilidir. Bitcoin'in arzı 21 milyon ile, bir diğer kripto para olan Litecoin ise 84 milyon arz ile sınırlandırılmıştır Arz rakamları bu sayılara ulaştığında sistemler tarafindan arz durdurulacak ve fiyatların artması kaçınılmaz olacaktır (Ateş, 2016, s. 358).

Ekonomilerde paranın, değişim aracı, hesap birimi ve değer saklama aracı olmak üzere üç temel fonksiyonu vardır (Krugman \& Wells, 2013, s. 383). Bitcoin'nin gerçek anlamda bir para birimi olarak nitelendirilip nitelendirilemeyeceği hususu paranın temel fonksiyonlarına bakarak değerlendirmek mümkündür. Kripto para birimlerinin itibari değeri bir ülkenin itibarı ile ilişkili olmayıp, kişilerin talep etme derecesine göre değeri oluşmaktadır. Bitcoin'nin son zamanlarda hemen hemen tüm piyasalarda tanınmış olmaya başlaması, kişiler tarafından kabul edilmeye ve alım satım işlemlerinde kullanılması paranın temel fonksiyonlarından biri olan değişim aracı olma özelliğini bünyesinde bulundurmaktadır. Burada temel problemlerden biri bitcoin'nin hala herkes tarafindan yeteri kadar bilinmemiş olmasıdır. Bu nedenle diğer temel para birimleri gibi değişim görevini tam olarak üstlendiği söylenemez. Bunun yanında bitcoin'nin diğer yatırım araçları ile değerlendirildiğinde birçok yatırım aracının arzının kayda değer miktarda var olmasına karşılık, bitcoin'nin arzının kısıtlı olması bir diğer yetersiz özelliğinden biri olarak karşımıza çıkmaktadır.

Son zamanlarda bitcoin'in yatırımcılar açısında talep görmesinin altında yatan temel nedenler, bitcoin'in fiyat değişimlerinde faydalanarak kar elde etme arzusu ve merak dürtüsüdür. Bu açıdan bakıldığın bitcoin'nin paranın temel fonksiyonlarından bir olan değer saklama aracı olma özelliğini daha çok üstlendiğini ifade etmek mümkündür. Bitcoin'nin arz miktarının sınırlı olduğu için zamanla değerinin artacağı yönünde bir beklenti oluşturmaktadır (Plassaras, 2013, s. 389). Son zamanlarda bitcoin'de yaşanan volatilite hareketi yatırım hususunda istikrarın sağlanamadığ 1 ve bitcoin'nin bir para biriminden ziyade spekülatif hareketlere açık bir yatırım aracı gibi hareket ettiğini ifade etmek mümkündür (Yermack, 2013, s. 1). Bitcoin'in getiri volatilitesi, diğer yatırım araçlarındaki volatilitelerinden yüksek gerçeklemesi bu durumu açıkça ortaya koymaktadır (Dwyer, 2015, s. 81). Bu özelliği nedeniyle Bitcoin'in oldukça volatil olması onu herhangi bir para birimi olarak görülebileceği gerçeğinden uzaklaştırmaktadır (Baur \& Dimpfl, 2017, s. 1). Bir yatırım aracının yatırım aracı olarak değerlendirilebilmesi için, Fama'nın (1970) verimli piyasalar hipotezine uygun hareket etmesi gerekmektedir. Piyasada farklı görüşler olmasına karşın bazı analistler Bitcoin piyasasının gerekli verimliliğe sahip olduğu savını ortaya koymuşlardır (Nadarajah \& Chu, 2017, s. 6). $\mathrm{Bu}$ açıdan değerlendirildiğinde bitcoin kullanıcılarının bitcoini alternatif bir işlem sistemi olarak görmeyip alternatif yatırım aracı olarak görüldüğ̈ söylenebilir (Glaser, Zimmermann, Haferkorn, Weber, \& Siering, 2014, s. 1).

\section{Literatür}

Yermack (2013), 19.07.2010-29.11.2013 dönemleri arasında ABD'de bitcoin'nin gerçekte bir para birimi olarak değerlendirilebileceği mi konusunda ortaya koyduğu çalışmada istatistiki olarak korelasyon ilişkisinden faydalanmıştır. Çalışma sonucunda bitcoin'nin önemli para birimlerinden ABD doları, Euro, İsviçre frangı ve Japon yeni ile altın arasında ilişki derecesinin çok düşük olduğu ifade etmiştir.

Baek ve Elbeck (2014), 2010-214 dönemleri arasında ABD'de bitcoin'in bir yatırım aracı mı yoksa spekülatif bir varlık mı olduğunu ortaya koymak için yaptıkları çalışmada, bitcoin'in fiyat değişim farkının bitcoin'in fiyat oluşumunda etkili olduğu sonucuna ulaşmışlardır. 
Glaser vd. (2014) 01.01.2011-08.10.2013 dönemleri arasında Mt Gox Bitcoin Borsasında bitcoin'in bir varlık mı ya da bir para birimi mi olarak ele alınması gerektiği hususunu GARCH modeli açıklamaya çalışmışlardır. Çalışma sonucunda bitcoin kullanıcılarının bitcoini bir para birimi olarak değil, spekülatif amaçlı bir varlık olarak kullandıkları sonucuna ulaşmışlardır.

Kristoufek (2015), 14.09.2011-28.02.2014 dönemleri arasında Çin'de Bitcoin'nin fiyatını belirlemede etkili olan piyasa sürücülerinin neler olduğunu belirlemeye yönelik çalışmada Wavelet Coherence Analizinden faydalanılmıştır. Çalışma sonucunda Bitcoin'nin fiyatının belirlenmesinde etkili olabilecek bir piyasa sürücüsünün ya da sürücülerinin olmadığı, Bitcoin'nin spekülatif özelliklere açık diğer yatırım araçlarından farklı nitelikte bir varlık olduğu sonucuna ulaşmıştır.

Dyhrberg (2015), 19.06.2010-22.05.2015 dönemleri arasında Büyük Britanya'da bitcoin'nin bir hedge enstrümanı olarak düşünülüp düşünülemeyeceği hususunu GARCH modeli açıklamaya çalışmıştır. Çalışma sonucunda bitcoin altın enstrümanı ile benzer hedge özelliği gösterdiği, bunun yanında FTSE 100 endeksine karşı bir hedge aracı olarak kullanılabileceği sonucuna ulaşmıştır.

Cheung vd. (2015), 17.07.2010-18.02.2014 dönemleri arasında Mt Gox Bitcoin Borsasının fiyat oluşumlarını Phillips-Shi-Yu Metodu ile ortaya koymaya çalışmışlardır. Çalışma sonucunda bitcoin'in fiyat oluşumlarında yaşanan volatilite hareketleri ve sağlıksız fiyat oluşumları Mt Gox Bitcoin Borsasının çökmesine neden olduğu sonucuna ulaşmışlardır.

Bouoiyour vd. (2015), 2010-2014 dönemlerini kapsayan Çin'de bitcoin'nin bir iş geliri veya spekülatif aptallık mı olduğunu ortaya koymak için yaptıkları çalışmada Granger Nedensellik analizinden faydalanmışlardır. Çalışma sonucunda bitcoin'nin fiyatı ile e-ticaret işlemleri ve yatırımcı çekiciliği arasında bir nedensellik ilişkisinin olduğunu gözlemlemişlerdir.

Atik vd. (2015), 2009-2015 yılları arasındaki Bitcoin günlük kur fiyatları ile dünyadaki en çok kullanılan çapraz kur fiyatları arasındaki etkileşimi ortaya koymaya çalıştıkları çalışmada bitcoin ile Japon Yen'inin birbirlerini gecikmeli olarak etkilediği ve Japon Yen'inden Bitcoin'e doğru tek yönlü bir nedensellik ilişkisinin varlığı tespit edilmiştir.

Carpenter (2016), Ocak 2012-Mayıs 2016 dönemleri arasında Mt Gox Bitcoin Borsasında bitcoin'nin diğer varlıklarla ilişki derecesini ve portföyde bir çeşitlendirme aracı olarak düşünülüp düşünülemeyeceği hususunda yaptıkları çalışmada finansal varlık fiyatlama modelinden(CAPM) faydalanmışlardır. Çalışmada bitcoin'nin diğer yatırım araçları ile ilişki derecesinin Pearson korelasyon matriksinde düşük olduğu bunun yanında bitcoin'in portföyde belli bir ağırlıkta yer alması durumunda katlanılan riskin, elde edilen getirinin altında kaldığını ifade etmiştir. Yazar bu durumun balon oluşumu ile nitelendirilebileceği ve özellikle 2013 yılında yaşanan ani volatilite hareketi bu durumla ilişkilendirilebileceğini iddia etmiştir.

Koçoğlu vd. (2016) 19.05.2014-06.09.2015 dönemleri arasında kripto paraların işlem hacmi açısından etkin olan Bitfinex (USD), Bitstamp (USD),Mt.Gox (USD), Btce
(USD), Okcoin (CNY), Kraken (EUR), Anx (JPY), Coinfloor (GBP) olmak üzere 8 farklı borsa ile ilişkisi analiz edilmiştir. Çalışmada ilişki derecesini ortaya koymak için Johansen Eşbütünleşme ve Granger Nedensellik analizlerinden faydalanılmıştır. Çalışma sonucunda kripto paralarının sadece 3 borsa ile ilişkisine rastlanılırken herhangi bir nedensellik ilişkisine ise rastlanılmamıştır.

Baur vd. (2017), 19.07.2010- 26.04.2017 dönemleri arasında bitcoin'nin bir değişim aracı ya da spekülatif bir varlık olarak düşünülüp düşünülemeyeceği hususunda yaptıkları çalışmada bitcoin'nin geleneksel yatırım araçları ile ilişki derecesinin düşük olduğu için portföylerde çeşitlendirme aracı olarak kullanılabileceği ifade etmişlerdir.

Bouri vd. (2017), Aralık 2013 öncesi ve sonrası dönemine ilişkin olarak enerji emtiaları ile bitcoin'in çeşitlendirme, hedge ve güvenli liman olabilme olma özellikleri açısından ele aldıkları çalıșmada GARCH-DCC modelini kullanmışlardır. Çalışmada yazarlar bir yatırım aracı diğer araçlarla ilişki derecesi çok düşük olduğu sürece portföyeler de çeşitlendirme aracı olarak görülebileceğini ifade etmişlerdir. Bunun yanında bir yatırım aracı diğer araçlarla herhangi bir ilişki derecesi yok ya da ilişki derecesi negatif ise hedge enstrümanı, piyasada risklerin arttığı dönemlerde diğer yatırım araçları arasında ilişki derecesi düşük ya da negatif ise güvenli liman olarak nitelendirilebileceğini ifade etmiş̧lerdir. Çalışma sonucunda bitcoin'nin enerji emtiaları açısından hedge ve güvenli liman özelliği taşıyabildiği, çeşitlendirme prensibinin zaman içinde farklılık gösterdiğini ifade etmişlerdir

Eswara (2017), 04.04.2017-21.07.2017 dönemleri arasında Hindistan 'da Bitcoin'nin rupi, sterlin ve yuan kurları arasındaki ilişki GARCH modeli ile ortaya konmaya çalışılmıştır. Çalışma sonucunda bitcoin-dupi kuru ile dolar kuru ile pozitif, sterlin ve yuan kurları arasında negatif korelasyon içinde olduğu sonucuna ulaşmıştır

Jin Lim ve Masih (2017), 2013-2017 dönemleri arasında islami şeriat prensiplerine göre oluşturulan hisse senedi endeksi ile bitcoin arasındaki ilişkiyi ortaya koydukları çalışmada M-GARCH-DCC, Continuous Wavelet Transforms (CWT), and Maximum Overlap Discrete Wavelet Transform (MODWT) metodlarını kullanmışlardır. Çalışma sonucunda islami niteliklere göre oluşturulan hisse senedi endeksi ile bitcoin arasında ilişkinin oldukça düşük olduğu bunun sonucunda bitcoin'nin bu endekste oluşturulan portföyler için bir çeşitlendirme aracı olarak kullanılabileceği sonucuna ulaşmışlardır.

Moro ve Kajtazi (2017), Çin'de 2013 dönemi öncesi ve sonrasının ele alındığı çalışmada bitcoin'nin portföy üzerinde etkisini incelemişlerdir. Çalışma sonucunda bitcoin'nin geleneksel yatırım araçları arasında çok düşük seviyelerde bir ilişkisinin olduğu, 2013 dönemi öncesinde bitcoin'in portföy performans1 üzerinde pozitif, 2013 sonrasında ise pozitif herhangi bir etkisi görülmemiştir.

\section{Veri Analizi ve Metodoloji}

Çalışmada bitcoin'nin hem fiyat oluşumu hem de bilinirliliği açısından ele alındığında 2013 Ocak ayı itibariyle başlamasının daha sağlıklı veriler verebileceği varsayımıyla, veri seti Ocak 2013- Mayıs 2018 dönemleri seçilmiştir. Çalışmanın amacı bitcoin'nin alternatif yatırım araçları 
karşısında uzun dönemli ilişkisinin değerlendirilmesi, değişkenler arasında nedensellik ilişkisinin var olup olmadığ 1 , portföylerde çeşitlendirme aracı olarak kullanılıp kullanılamayacağı ve finansal sistemde yeni bir yatırım aracı olarak değerlendirilip değerlendirilemeyeceği hususunu ortaya koymaktır. Çalışmada uluslararası çerçevede nitelikli, güvenilir ve işlem hacmi açısından yüksek olan S\&P 500, Nasdaq, Londra FTSE, Dow 30, Tokyo NIKKEI 225, borsaları analize tabi tutulmuştur. Eş bütünleşme testleri çalışmada yer alan değişkenler arasında uzun dönemli ilişkinin ortaya konmasında kullanmaktadır. Literatürde yaygın bir şekilde kullanılan Johansen ve Engle-Granger gibi eş bütünleşme testleri değişkenlerin aynı dereceden bütünleşik olması gerektirdiği için bu durumu aşabilmek için Paseran vd (2001) tarafindan ortaya koyan farklı dereceden bütünleşik olmasına olanak sağlayan ARDL (Autoregressive Distributed Lag) yaklaşımı çalışmada kullanılmıştır. Bunun yanında diğer yatırım araçlarından Petrol, Altın, BIST100, Bloomberg Emtia Endeksi (BEE), ABD 10 Yillik bono faizinin BTC/USD ilişki derecesini ARDL testi ile ortaya koyulmaya çalışılmıştır.

Sınır testi çalışmada kullanılan değişkenler arasında uzun dönemli bir ilişkinin olup olmadığını ortaya koymaktadır. Sınır testi uygulandığında test istatistiği kritik sınırı geçtiğinde kısa ve uzun dönemde katsayılar tahmin edilebilmektedir. Eşbütünleşme testleri uzun vadede ve gözlem sayısının fazla olduğu veri setine uygulandığında anlamlı sonuçlar vermesine karşın, ARDL modeli daha küçük örneklemlere uygulansa bile sağlıklı sonuçlar verebilmektedir. ARDL yöntemi 3 aşamadan oluşmakta olup, ilk aşamada değişkenler arasında uzun dönemli ilişkinin olup olmadığı ortaya koyulmaktadır. İlişkinin mevcudiyetine bağlı olarak ikinci ve üçüncü aşamalara geçilip olup, uzun dönemli ilişkinin var olmasından sonra kısa ve uzun vadedeki katsayılar belirlenmektedir.

Durağanlık zaman serilerin yer alacağı çalışmalarda test edilmesi gereken bir durumdur. Çalışmada ham verilerin kullanımı yerine logaritmik getiri değerleri kullanılmıştır. Ham veriler yerine logaritmik değerlerin kullanılmasının nedeni, logaritmik değerlerin alınarak veri değerlerinin küçültmesinin sağlanmasıdır. Bunun yapılmasında ki temel amaç ham verilerin logaritmik değerleri alındığında küçülmesi ve bilgi kaybının yaşanmamış olmasının sağlanmasıdır. Bunun yanında logaritmik değerlerin alınmasında bir diğer amaç ise oto korelasyon sorununun ortadan kaldırılıp, serinin volatil yapısını durağan hale getirmektir. Çalışmada kullanılan değişkenlere ait yıllar itibarıyla fiyat kapanış değerleri ve logaritmik getiri değerlerinin değişimi Şekil 1'de yer almaktadır.

Şekil 1. Değişkenlere Ait Yıllar İtibarıyla Kapanış Değerleri ve Logaritmik Getiri Değerleri
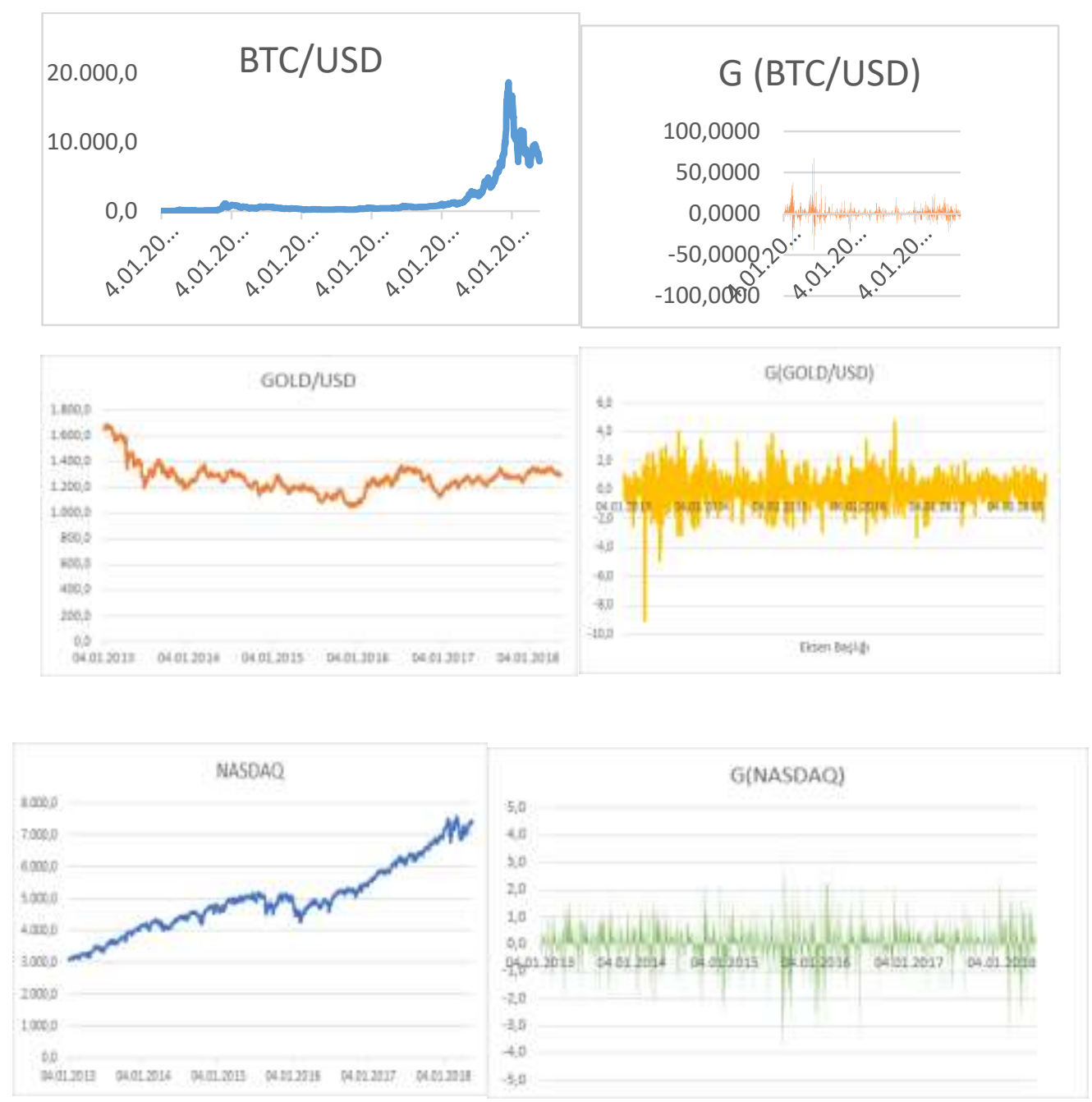

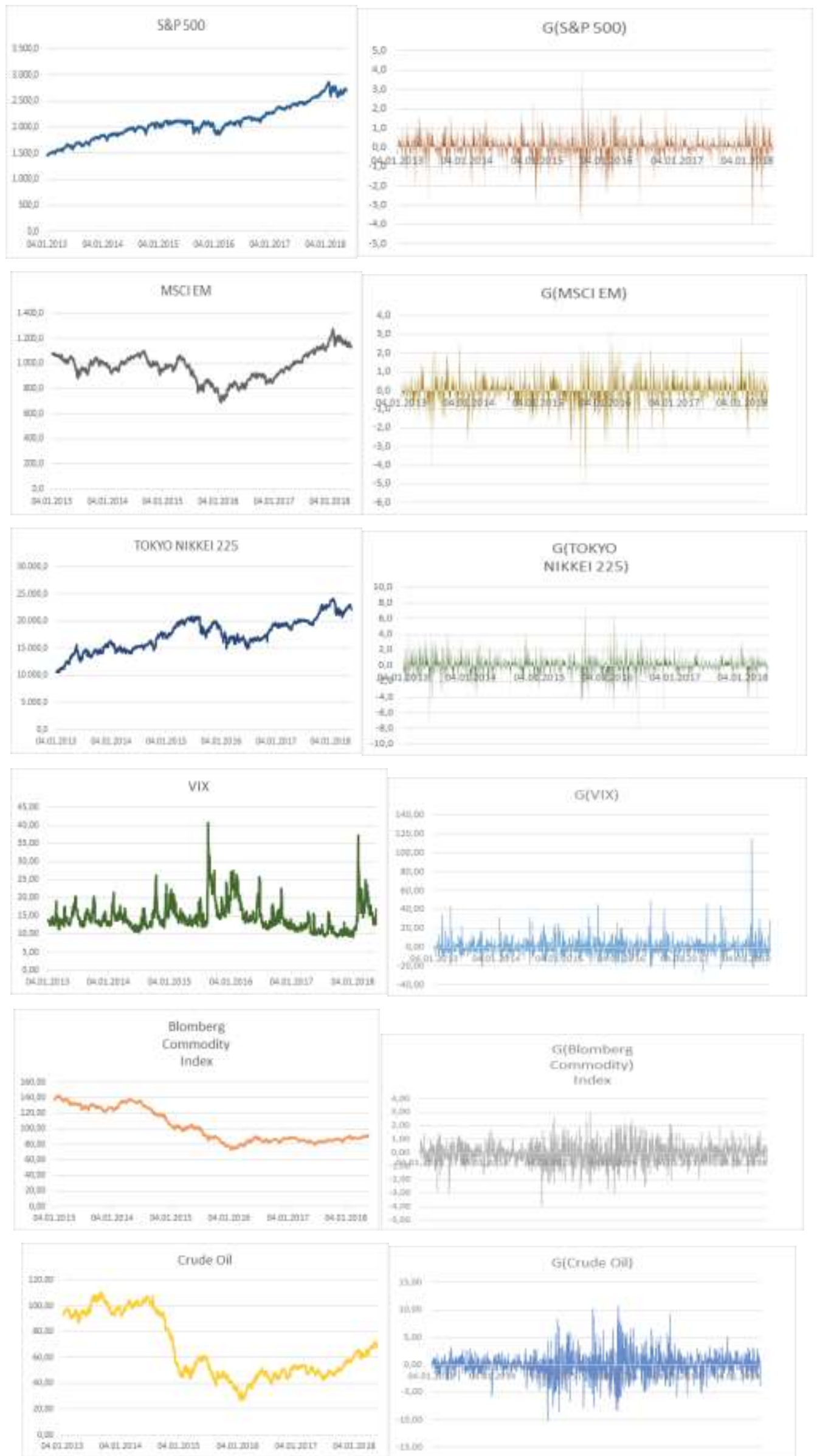

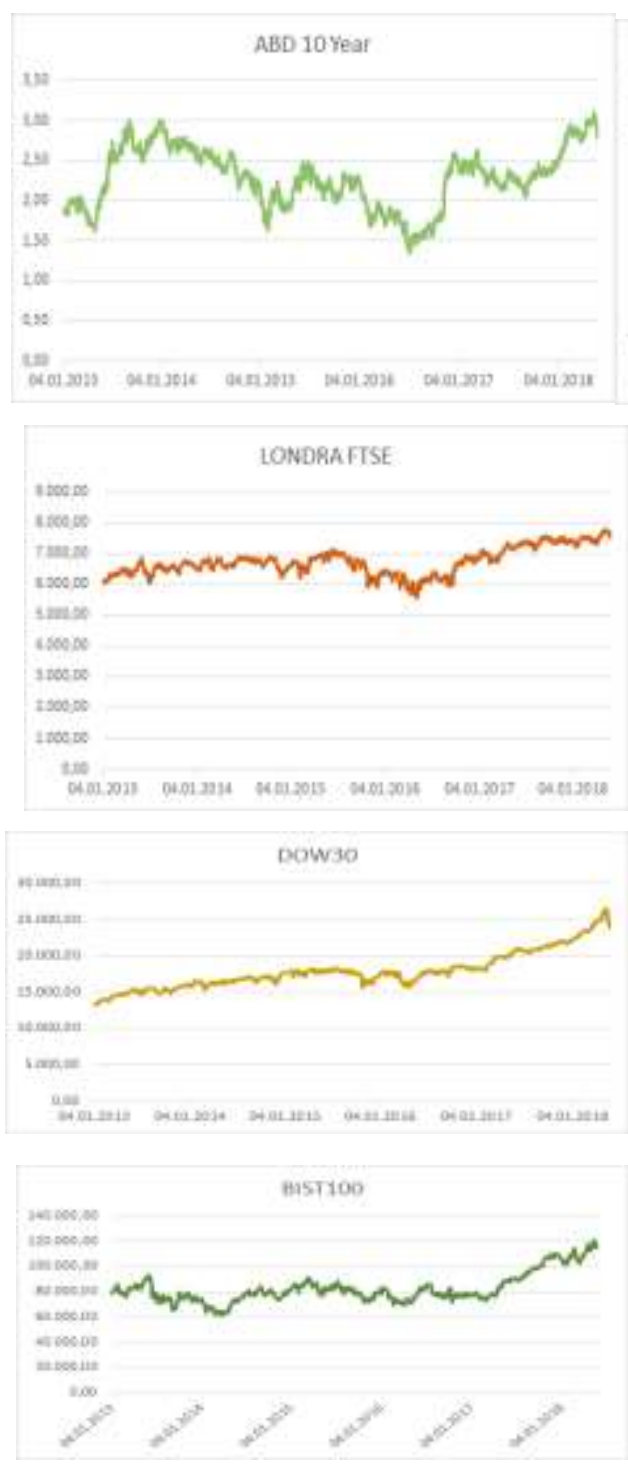

ARDL testinin uygulamadan önce ilgili verilerin durağanlık koşulunu sağlayıp sağlayamadığının tespiti gerekmektedir. Durağanlı̆̆ın sağlanamadığı durumlarda ARDL testinin uygulanması yanıltıcı sonuçlar verebilir. Değişkenlere ait zaman serilerinin durağan olup olmadığının tespiti için genişletilmiş Dickey-Fuller ve PP (Phillips \& Perron, 1988) testleri sabit ve sabit-trendli olacak şekilde uygulanmıştır. Dickey-Fuller testi, gözlenen serilerde birim kökün varlığının (serinin durağan olmadığı) olup olmadığının belirlenmesinde kullanılan bir testtir. Uygulamalarda serinin birim kök taşıyıp taşımadığının saptanması için mutlak suretle DF (Dickey-Fuller) testinin yapılması şart niteliğinde bulunmaktadır. İlgili değişkenlere ait gözlem değerleri bir önceki döneme ait değere bölünmesi sonucunda doğal logaritması sonucunda ortaya çıkan getiriler aşağıdaki formül ile bulunmuştur. (Beninga, 2000, s. 22)

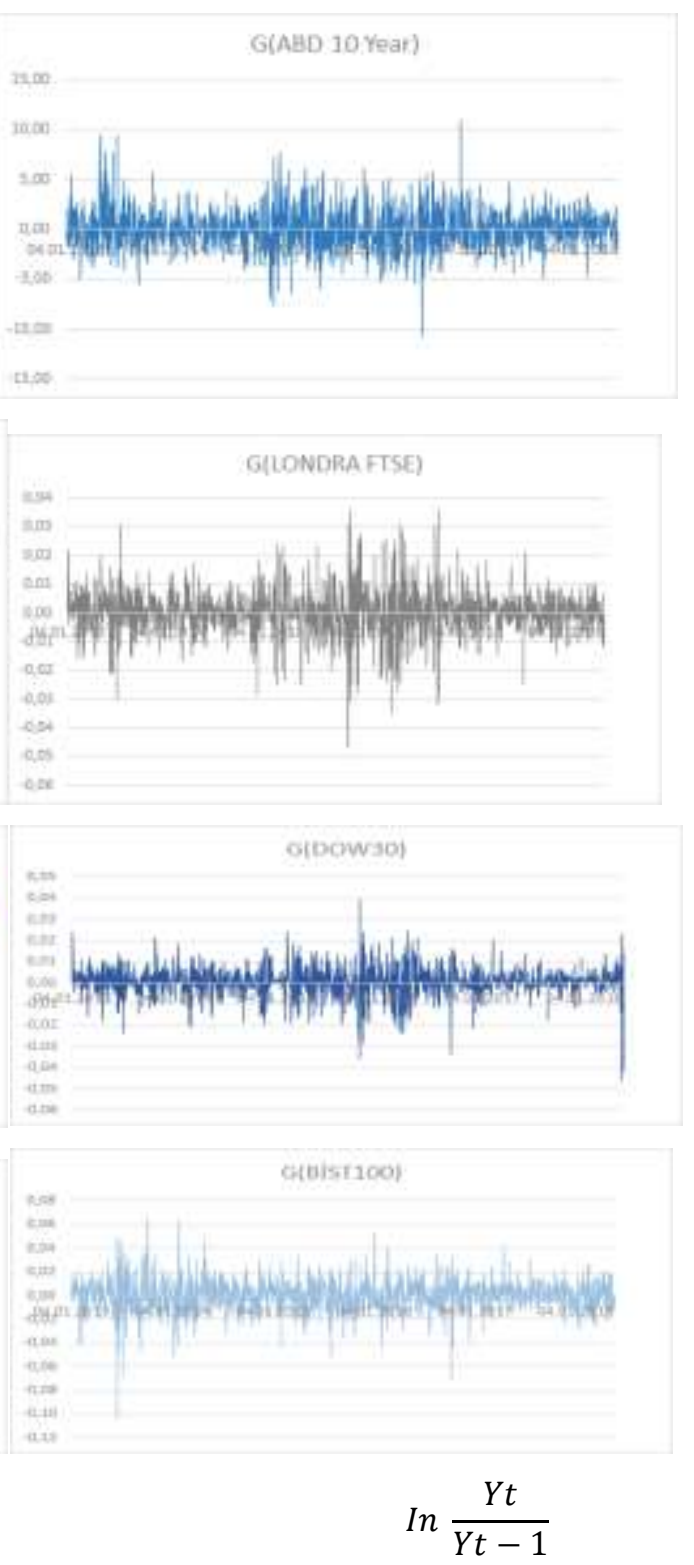

Durağanlı̆̆ı ortaya koymak için Dickey ve Fuller (1981) tarafindan geliştirilen Augmented Dickey-Fuller (ADF)birim kök testi formülü aşağıda yer almaktadır (Gujarati D. , 1999).

$$
\Delta Y t=\beta 1+\beta 2 \times t+\delta . Y t-1+\alpha_{i} \sum_{i=1}^{m} \Delta Y t-i+\varepsilon_{t}
$$

$\Delta \mathrm{Yt}=$ Değişkenin birincil fark1

$\mathrm{t}=$ Trend Değişkeni

$\Delta \mathrm{Yt}-\mathrm{i}=$ Gecikmeli fark

$\varepsilon \mathrm{t}=$ Hata terimi 
Tablo 1. Sabit Terimli ve Trendli Modelin ADF ve PP (Phillips \& Perron) Test Sonuçları

Sabit Terimli ve Trendli Model

\begin{tabular}{lcccccccc}
\hline & \multicolumn{4}{c}{ Düzey } & \multicolumn{4}{c}{ Birinci Sura Fark } \\
\cline { 2 - 9 } Değişkenler & \multicolumn{2}{c}{ ADF } & \multicolumn{2}{c}{$\begin{array}{c}\text { PP(Phillips \& } \\
\text { Perron) }\end{array}$} & \multicolumn{2}{c}{ ADF } & \multicolumn{2}{c}{$\begin{array}{c}\text { PP (Phillips \& } \\
\text { Perron) }\end{array}$} \\
\cline { 2 - 9 } & $\mathbf{t}^{*}$ istatistiği & P Değeri & $\mathbf{t}^{*}$ istatistiği & P Değeri & $\mathbf{t}^{*}$ istatistiği & P Değeri & $\mathbf{t}^{*}$ istatistiği & P Değeri \\
\hline Dow30 & $-0,367$ & 0,456 & $-0,985$ & 0,126 & $-21,975$ & 0 & $-31,124$ & 0,001 \\
Nasdaq & $-1,045$ & 0,345 & $-1,143$ & 0,445 & $-21,643$ & 0 & $-29,987$ & 0 \\
Londra FTSE & $-0,865$ & 0,945 & $-3,654$ & 0,356 & $-20,634$ & 0 & $-35,643$ & 0,001 \\
Tokyo NIKKEI225 & $-1,097$ & 0,923 & $-4,154$ & 0,945 & $-21,154$ & 0 & $-35,128$ & 0,001 \\
S\&P500 & $-2,765$ & 0,123 & $-3,453$ & 0,543 & $-13,564$ & 0 & $-34,564$ & 0 \\
BTC/USD & $-1,123$ & 0,765 & $-1,123$ & 0,675 & $-11,127$ & 0 & $-36,145$ & 0 \\
GOLD/USD & $-1,456$ & 0,996 & $-7,674$ & 0,992 & $-27,4$ & 0 & $-37,424$ & 0,001 \\
MSCI EM & $-2,456$ & 0,345 & $-7,123$ & 0,654 & $-22,654$ & 0 & $-35,125$ & 0 \\
Blomberg & $-3,789$ & 0,125 & $-3,167$ & 0,123 & -23 & 0 & $-35,167$ & 0,001 \\
Commodity Index & $-1,234$ & 0,345 & $-3,354$ & 0,167 & $-21,234$ & 0 & $-37,234$ & 0 \\
Crude Oil & $-0,234$ & 0,912 & $-1,165$ & 0,934 & $-14,243$ & 0 & $-35,554$ & 0,001 \\
ABD 10 Years & $-1,234$ & 0,124 & $-2,591$ & 0,675 & $-21,984$ & 0 & $-32,984$ & 0 \\
BIST100 & & & & & & & 0
\end{tabular}

Tablo 1'de analizde yer alan diğer değiş̧enler üzerinde yapılan ADF ve PP (Phillips \& Perron) birim kök testi sonuçları incelendiğinde sabit terimli model ve sabit terimsiz-trendsiz modelde yer alan değişkenler durağan bir yapı sergilemedikleri gözlemlenmiş̧tir. Birinci farkı alınan tüm değişkenler her modelde durağan biçime dönüştüğü gözlemlenmektedir.

Yaptığımız uygulamada temel amaç bitcoin'nin en büyük borsalar ile Petrol, Altın, BIST100, Bloomberg Emtia Endeksi (BEE), MSCI EM( Gelişmekte Olan Piyasa Endeksi) ve ABD 10 Yıllık bono faizi gibi yatırım araçları ile ilişki derecelerini ortaya koymak ve bu değişkenler ile bitcoin arasında eş bütünleşme olup olmadığının tespitini sağlamaktır. Bunu yapmakta temel amaç çalışmanın ana konusunu oluşturan bitcoin'nin diğer yatırım araçlarına alternatifi olarak bir hedge enstrümanı olarak görülüp görülemeyeceği hususudur. Bunun ortaya konabilmesi için eş bütünleşme metodunun gerçekleştirilmesi gerekmektedir.

\section{ARDL Testi Sonuçları}

İstatistiki olarak değişkenler arasında kurulan korelasyonlar değişkenlerin arasında ilişkinin var olup olmadığ hususunda bilgi vermesine rağmen, ilişkinin yönü ve nedenselliği hakkında bilgi verememektedir. İlişkiyi ortaya koymak için kullanılan regresyon denklemi, sadece bağımlı değişken ile bağımsız değişken arasındaki ilişki ortaya konmasına karşın bunun nedensellik ilişkisini ortaya koyamamaktadır (Gujarati D. N., 2004, s. 696).

Eş bütünleşme testleri çalışmada yer alan değişkenler arasında uzun dönemli ilişkinin ortaya konmasında kullanmaktadır. Literatürde yaygın bir şekilde kullanılan Johansen ve Engle-Granger gibi eş bütünleşme testleri değiş̧kenlerin aynı dereceden bütünleşik olması gerektirdiği için bu durumu aşabilmek için Paseran vd (2001) tarafından ortaya koyan farklı dereceden bütünleşik olmasına olanak sağlayan ARDL(Autoregressive Distributed Lag) yaklaşımı çalışmada kullanılmıştır (Pesaran, Shin, \& Smith, 2001).

Literatür çalışmalarda ilgili dizilerin eş bütünleşik olup olmadığı hususunda çeşitli yöntemler kullanılmaktadır.

Bu çalışmada bitcoin'nin araştırmaya konu olan değişkenler arasında uzun vadeli hareketlerini yönlendiren ortak faktörlerin analizinin sağlanması için ARDL testi uygulanmıştır. Testin uygulanabilmesi için tüm değişkenlerin durağan olması koşulunun sağlanması gerekmektedir. Tüm değişkenlerin birinci derece farklarının durağan olduğu tespit edilmiştir. Araştırmada eş bütünleşmenin incelenmesi için ARDL testi çalışma için uygun yöntem olduğuna karar verildikten sonra tahmin edilecek ARDL modeli için en uygun gecikme uzunluğunun belirlenmesi gerekmektedir. Bu aşamada farklı gecikme kombinasyonlarında sınanan değişkenler, bilgi kriteri (AIC: Akaike bilgi kriteri, SC: Schwarz bilgi kriteri, HQ: HannanQuinn bilgi kriteri) en düşük değeri alan model, en uygun model olarak belirlenmektedir.

AIC, SC ve HQ gibi bilgi kriterleri VAR modelinde en uygun gecikme uzunluğunun ortaya konmasında yardımcı olmaktadırlar. AIC, SC ve HQ için en düşük değeri veren gecikme sayısı en uygun gecikme uzunluğunu ifade etmektedir. Yapılan çalışma sonucunda bilgi kriterleri en uygun gecikme uzunluğunun üçüncü gecikme olduğu ortaya çıkmıştır. Üçüncü gecikme sayısının en uygun gecikme uzunluğunu söyleyebilmek için aynı zamanda ilgili gecikmede oto korelasyon sorununun olup olmadığı LM testi ile sınanmıştır. 
Tablo 2. ARDL Sınır Testi Sonuçları

\begin{tabular}{lcc}
\hline F istatistiği & \multicolumn{2}{c}{$4.798(0,0002)$} \\
\hline $\begin{array}{l}\text { Optimum Gecikme } \\
\text { Uzunluğu }\end{array}$ & {$[3,7,5,2,1,8,9,4,10,12,11]$} \\
\hline \multirow{2}{*}{ Anlamlıık Seviyesi } & \multicolumn{2}{c}{ Kritik Değer } \\
\cline { 2 - 3 } & Alt Sınır & Üst Sınır \\
\hline \multicolumn{1}{c}{$5 \%$} & 4.19 & 5.45 \\
\hline $10 \%$ & 3.53 & 4.95 \\
\hline \multicolumn{2}{c}{ Testler } & \multicolumn{2}{c}{3.64} \\
\hline Tanısal (Diagnostik) & \multicolumn{2}{c}{0.445} \\
\hline$R^{2} \quad$ İstatistikler \\
\hline Düzeltilmiş $R^{2}$ & \multicolumn{2}{c}{0.398} \\
\hline F-istatistiği & $5.423(0.000)$ \\
\hline Breusch-Godfrey LM & $0.345(0.654)$ \\
\hline ARCH LM & $3.001(0.123)$ \\
\hline Jarque-Bera Normality & $0.032(0.876)$ \\
\hline Ramsey Reset & $1.032(0.897)$ \\
\hline
\end{tabular}

Tablo 2'de yer alan bilgiye göre $\% 5$ anlamll1lk seviyesinde F değeri üst sınır değerinden küçük olduğu için değişkenler arasında eş bütünleşme ilişkisinin olmadığı tespit edilmiştir. Bir başka ifadeyle bitcoin ile ilgili diğer değişkenler arasında uzun dönemli bir ilişkinin olmadığı tespit edilmiştir. Modelde otokorelasyon olup olmadığ 1 Breusch-Godfrey LM Testi ile sınanmış ve otokorelasyon sorunu olmadığı tespit edilmiştir. Bunun yanında modelde değişen varyans sınaması da ARCH LM ile yapılmış ve değişen varyans sorunu olmadığı tespit edilmiştir. Hata teriminin normal dağılıma sahip olup olmadığı Jarque-Bera Normality ile test edilmiştir. Ramsey Reset ile model kurmada herhangi sorun olmadığ tespit edilmiştir. Bu aşamadan sonra en uygun gecikme uzunluğu tespit ettikten sonra modelin tahminine ilişkin bilgiler Tablo 3'te yer almaktadır.

Tablo 3. ARDL Modeli Uzun Dönem Katsayıları

\begin{tabular}{lccc}
\hline Bağımsız Değişkenler & Katsayı & $\begin{array}{c}\mathbf{t} \\
\text { İstatistik }\end{array}$ & Olasılık \\
\hline LOG Dow30 & 20.3452 & 7.1431 & 0.3454 \\
\hline LOG Nasdaq & 6.1243 & 1.4354 & 0.2343 \\
\hline LOG Londra FTSE & 0.3465 & 4.3454 & 0.2131 \\
\hline LOG Tokyo & -0.7234 & -1.4323 & 0.0651 \\
NIKKEI225 & -0.5643 & 1.2251 & 0.0854 \\
\hline LOG S\&P500 & 0.7711 & -2.3525 & 0.0834 \\
\hline LOG GOLD/USD & 0.1243 & -0.5436 & 0.0054 \\
\hline LOG MSCI EM & -0.7645 & 2.6541 & 0.3423 \\
\hline LOG Blomberg & & \\
Commodity Index & -0.5676 & 4.6549 & 0.2123 \\
\hline LOG Crude Oil & -0.1243 & 3.7643 & 0.1265 \\
\hline LOG ABD 10 Years & 1.6534 & 2.8761 & 0.5643 \\
\hline LOG BIST100 & $-0,3278$ & 2,1987 & 0,0085 \\
\hline KUKLA DEĞİiSKEN & $-2,2354$ & $-2,7654$ & 0,0001 \\
\hline C & & \\
\hline Bağımlı Değişken: & & & \\
LOGBITCOIN & & &
\end{tabular}

ARDL uzun dönem testi istatistiki sonuçlara baktığımızda $\% 5$ anlamlılık seviyesinde istatistiki olarak anlamlı olmadığ 1 tespit edilmiştir. Bir başka ifadeyle seriler arasında eş bütünleşme olmadığı kabul edilmektedir. Sonuç olarak çalışmada yer alan tüm değişkenlerin bitcoin ile uzun dönemli bir ilişkinin mevcudiyeti bulunamamışıtır. Bir ilişkinin mevcudiyetinin bulunmamasında $\mathrm{ki}$ temel nedenlerden biride bitcoin'nin yüksek varyans'a sahip iken diğer tüm değikenlerin düşük varyansa olmasa sahip olmalarından kaynaklanmaktadır. Bunun yanında bir diğer neden ise bitcoin dışında diğer yatırım araçlarının belirli bir merkezi otoriteye bağlı olup belirli kurallar bütünü altında işlem görmesinden kaynaklanmış olabilme ihtimalidir. Çünkü daha öncede ifade edildiği gibi Bitcoin 2008 yllında Stoshi Nakamoto tarafindan herhangi bir otoriteye bağlı olmadan oluşturulmuş sanal bir varlığ ifade etmektedir

\section{Bulgular}

Bitcoin'in diğer yatırım araçlarıyla ilişkisinin bulunmaması buradaki yatırımcıların ilgili konuya duyarsız kaldıkları şeklinde değerlendirilmeyeceği, yatırım kararlarında Bitcoin'deki gelişmeleri bağımsız düşündükleri ya da yorumladıkları şeklinde yorumlanabilmektedir.

Kripto para birimlerinden bitcoin'in fiyatında yaşanan volatilite hareketleri, fiyat değişimi sonucunda yaşanan kazanç iştahı ve merak unsurları yatırımcıların ilgisini çeken bir finansal varlık olmasına neden olmuştur. Bitcoin'in piyasada derinlik sağlamaya başlamasıyla birlikte, bitcoin'nin diğer yatırım araçlarıyla ilişkisinin ortaya konması gerekliliği ortaya çıkarmıştır. Yapılan çalışmalarda bitcoinin bir yatırım aracı, portföylerde çeşitlendirme aracı, bir hedge enstrümanı olarak değerlendirilip değerlendirilemeyeceği ve bir para birimi olup olmadığ 1 hususu tartışılmaya devam etmektedir. Yaptığımız çalışmada her ne kadar bitcoin'nin diğer yatırım araçları ile uzun dönemli bir ilişkisinin olmadığı ortaya konmuş olsa da bunun yatırımcılarının bitcoin'i bağımsız olarak bir yatırım aracı olarak görmedikleri anlamına gelmemektedir. Yatırımcılar yatırım kararlarını alırken bitcoini referans olarak almadıkları sonucunu çıkartabiliriz. Yapılan çalışmalara bakıldığında bitcoin'nin bu kadar geniş yelpazede diğer yatırım araçlarıyla ilişkisi ortaya konulduğu çalışmaya rastlanmaması ve yapılan çalışmaların genellikle nedensellik ilişkisi üzerinde durulması çalışmanın özgünlüğ̈̈nü ortaya koymaktadır. Ülkemiz açısında ele alındığında bitcoin'nin BIST 100 ile ilişkisinin olmaması Türkiye'de yatırımcılar tarafindan bitcoin'in yeteri kadar bilinmemesi, sığ işlem hacmi, mevzuatta 'ki boşluklar ve piyasay1 geriden takip etme gibi nedenlerden dolayı bir ilişskinin mevcudiyeti bulunamamıştır.

Bitcoin'nin $\mathrm{ABD}$ ve Çin borsasında en çok işlem gördüğü düşünüldüğünde, bitcoin'in fiyat oluşumu üzerinde yatırım kararlarııın alınmasında beklentileri ön plana çıkmaktadır. Yapılan bir çalışmada kripto para birimlerinin Kuzey Amerika ve Uzakdoğu'da diğer bölgelere göre daha çok personel çalıştırıldığını göstermesi, fiyat oluşumlarında bu ülkedeki yatırımcıların beklentilerine göre hareket edildiğini daha da açık hale getirmektedir (Hileman \& Rauchs, 2017, s. 25).

Bitcoin'nin emtia olarak düşünülüp düşünülmeyeceği hususunda henüz somut bir durum mevcut değildir. Fakat 
Aralık 2017 itibariyle bitcoin'nin ABD Chicago Emtia Borsası'nın (CME) Bitcoin vadeli işlem piyasasında işlem görmeye başlaması, bitcoin'nin bir emtia olarak değerlendirilip değerlendirilmeyeceği hususunda emtia olarak ele alınabileceğini ortaya çıkarmaktadır.

Bitcoin'nin işleyiş mekanizması herhangi bir merkezi otoriteye ya da ekonomiye bağlı olmadığı için uluslararası veri akışından etkilenmemektedir. Özellikle Türkiye gibi diğer gelişmekte olan ülkelere baktığımızda dışa açıklık dereceleri yüksek olduğu ve ekonomilerinde yaşanan ani volatilite hareketleri açısından değerlendirildiğinde, bitcoin'in haber akışından etkilenmemesi bu tür ülkelerde yatırımcılar açısından bir hedge enstrümanı olarak değerlendirilip değerlendirilemeyeceği durumunu ortaya çıkarmaktadır. $\mathrm{Bu}$ açıdan bakıldığında gelişmekte olan ülkelerin kendilerine has riskleri azaltabilecek, mevcut istemlerin tıkandığ 1 noktada ve yaşanabilecek volatilite hareketlerine karşı bitcoin alternatif ürün olarak değerlendirilebilmesi mümkündür.

Bitcoin'nin güvenli bir liman olarak bir hedge enstrümanı olarak görülüp görülmeyeceği hususunda gelindiğinde, özellikle Kuzey Kore ve ABD yaşanan gerilim dönemlerinde ve birkaç ülkede yaşanan darbe dönemlerinde (Zimbabve, Ukrayna) bitcoin'nin fiyatında görülen artış, yatırımcılar açısından belirsizlik dönemlerinde hedge enstrümanı olarak görülebileceğini ifade etmek mümkündür.

Bitcoin ile döviz kurları arasındaki ilişkiye rastlanılmaması, bitcoinin miktar ve piyasa değeri açısından ele alındığında itibari paralar ile karşılaştırıldığında söz konusu değerlerin ve miktarın düşük olmasından kaynaklanabileceği düşünülmektedir. Çünkü bitcoin değerinde yaşanan volatilite diğer itibari paralarda gözlemlenmektedir. Bunun nedeni itibari paraların arkasında merkezi bir otoritenin olmasından kaynaklanmaktadır. Günümüzde merkez bankalarının temel görevleri fiyat istikrarını sağlayacak para politikaları ve araçları belirlemektir. Bitcoin de ise bu durum söz konusu olmayıp, bitcoine duyulan güven merkezi bir otorite ile değil, farklı algoritmaya sahip şifreleme tekniğinden kaynaklanmaktadır.

Çalışmada yapılan analiz sonucunda diğer yatırım araçları ile Bitcoin arasında herhangi bir ilişki derecesi ve nedenselliğin ortaya çıkmaması, Bitcoinin diğer yatırım araçlarından bağımsız hareket ettiğini göstermektedir.

Dünya'da teknolojik olarak gelişmiş ülkelerde nakite dayalı olmayan bir altyapı üzerinde çalışmalar yapmaları gelecekte nakit paranın yerini dijital paralar alacağını göstermektedir. Merkez bankalarının blok zincirine dayalı araştırmaları, bu konuya ilgi duyduklarını göstermektedir. Kanada ve Singapur Merkez Bankaları arasında blok zincir kullanarak yapılan para transferinin başarılı bir şekilde gerçekleşmesi gelecekte kripto paralarının yer edinmeye başlayacağının göstergesi olarak nitelendirilebilir. Kripto paraların merkezi otoriteye bağlı itibari paralara meydan okuması, ülkelerin kendi dijital paralarını oluşturma ihtimalini kuvvetlendirmektedir. Bu konuda ilk adımı atan, Estcoin isimli ilk resmi dijital para birimini geliştiren Estonya olmuştur. Japonya da benzer şekilde J Coin isimli bir dijital para birimi üzerinde çalışmalarına devam etmektedir

Bitcoin'nin yatırım aracı ya da itibari paralar gibi ödeme aracı olarak değerlendirilip değerlendirilemeyeceği hususunda geleneksel paranın bünyesinde taşıdığı değer saklama aracı olma ve değișim aracı olma fonksiyonu taşıyamadığı gözlemlenmektedir. Her ne kadar bir ödeme aracı olarak kullanılmaya başlansa da henüz yeteri kadar yaygın kullanılması bunu açıkça ortaya koymaktadır. Değerinde yaşanan volatil hareket, bitcoin'in spekülatife açık bir yatırım aracı olarak görülmesine ve yatırımcıların bitcoine mesafeli kalmasına neden olmuştur. Bunun yanında Bitcoin'nin standart sapmasının diğer yatırım araçlarına göre yüksek olması portföylerde çeşitlendirme amacıyla kullanmasına engel teşkil etmektedir.

\section{Sonuç}

$\mathrm{Bu}$ çalışma finansal sitemde yeni yer edinmeye çalışan Bitcoin'i anlamak ve diğer yatırım araçları arasında ilişkisinin olup olmadığını ortaya koymaktır. Çalışmada bitcoin birçok borsa ile ilişkisi ortaya konmasının yanında birkaç para birimi ile ilişkisi de incelenmeye çalışılmıştır. Çoğu yatırımcı hakkında herhangi bir fikir sahibi olmadığı bir varlığı anlamlandırmak için, en iyi bildiği varlık ya da varlıklarla benzerlikler ya da farklılıklar arar.

2003 yılından sonra Bitcoin'nin getirisinde yaşanan kayda değer artış hem bireysel hemde kurumsal yatırımcılarının bitcoin üzerinde odaklanmalarına neden olmuştur. Yaşanan bu artış bitcoin'nin gerçekte bir yatırım aracı olup olamayacağı konusunu gündeme taşımıştır. Bitcoin'nin yatırım aracı olarak değerlendirilebilmesi için bir takım kriterleri sağlaması gerekmektedir. $\mathrm{Bu}$ kriterler arasında yatırım piyasasının Fama'nın (1970) verimli piyasa hipotezine uyum sağlayacak şekilde işlemlerin gerçekleşmesi yer almaktadır.

Diğer bir kriter olarak portföyde çeşitlendirme prensibini sağlayıp sağlayamadığı hususudur. Geçmişten günümüze kadar altın'nın birçok yatırımcı açısından hedge enstrümanı olarak düşünüldüğünde, bitcoin'nin altın gibi hedge enstrümanı olarak düşünülüp düşünülemeyeceği bu makale açısından bu ilişkinin ortaya konmasının önemini daha da arttırmıştır.

Ekonomilerde paranın, değişim aracı, hesap birimi ve değer saklama aracı olmak üzere üç temel fonksiyonu vardır. Kripto para birimlerinin ve Bitcoin'nin gerçek anlamda bir para birimi olarak nitelendirilip nitelendirilemeyeceği hususu paranın temel fonksiyonlarına bakarak değerlendirmek mümkündür. Kripto para birimlerinin itibari değeri bir ülkenin itibarı ile ilişkili olmayıp, kişilerin talep etme derecesine göre değeri oluşmaktadır. Bitcoin'nin son zamanlarda hemen hemen tüm piyasalarda tanınmış olmaya başlaması, kişiler tarafından kabul edilmeye ve alım satım işlemlerinde kullanılması paranın temel fonksiyonlarından biri olan değişim aracı olma özelliğini bünyesinde bulundurmaktadır. Burada temel problemlerden biri bitcoin'nin hala herkes tarafindan yeteri kadar bilinmemiş olmasıdır. Bu nedenle diğer temel para birimleri gibi değişim görevini tam olarak üstlendiği söylenemez. Bunun yanında bitcoin'nin diğer yatırım araçları ile değerlendirildiğinde birçok yatırım aracının arzının yeteri kadar olduğu fakat bitcoin'nin arzının kısıtlı olması, bitcoinin bir diğer yetersiz özelliğinden biri olarak karşımıza çıkmaktadır. Bitcoin'nin bir para statüsü ya da emtia olarak görüleceği hususunda iki görüş ön plana çıkmaktadır. Bitcoin'nin bir para birimi olarak düşünüleceği görüşüne göre, bitcoin'nin hızlı bir şekilde transfer edilebilmesi ve değerinin her geçen gün artması beklentisi onu para birimi olarak düşünülebileceği 
olgusunu ön plana çıkarmaktadır. Buna karşılık olarak bitcoin'nin fiyat değişimlerinde yaşanan volatilite hareketleri kişi ya da kurumların mali risklerini arttıracaktır. Bitcoin herhangi bir merkeze ya da otoriteye bağlı olmadan kriptografik altyapıya sahip bir para birimi olarak karşımıza çıktığı için elinde bulunduran devlet ya da devletlerin otorite gücünden bağımsız hareket edecektir. Bitcoin'nin bir emtia olarak düşünüleceği hususunu temel alan görüşe göre, bitcoin'ni arzının sınırlı olması ve herhangi bir merkezi otoriteye bağlı olmama özelliği ile bitcoin'ni altın gibi görülebileceğini ortaya koymaktadır.

Bitcoin'nin emtia olarak düşünülüp düşünülmeyeceği hususunda henüz somut bir durum mevcut değildir. Fakat her ne kadar bitcoin'nin arzının sınırlı olması ve herhangi bir merkezi otoriteye bağlı olmama özelliği ifade edilse de Aralık 2017 itibariyle bitcoin'nin ABD Chicago Emtia Borsası'nın (CME) vadeli işlem piyasasında işlem görmeye başlaması, bitcoin'nin bir emtia olarak değerlendirilip değerlendirilmeyeceği hususunda emtia olarak düşünülebileceğini ortaya çıkarmaktadır. Ancak Bitcoin'nin ABD ve Çin borsasında en çok işlem gördüğü düşünüldüğünde, bitcoin'in fiyat oluşumu üzerinde yatırım kararlarının alınmasında beklentileri ön plana çıkmaktadır. Yapılan bir çalışmada kripto para birimlerinin Kuzey Amerika ve Uzakdoğu'da diğer bölgelere göre daha çok personel çalıştırıldığını göstermesi, fiyat oluşumlarında bu ülkedeki yatırımcıların beklentilerine göre hareket edildiğini daha da açık hale getirmektedir

Bitcoin herhangi bir merkeze ya da otoriteye bağlı olmadan kripto grafik altyapıya sahip bir para birimi olarak karşımıza çıktığ 1 için elinde bulunduran devlet ya da devletlerin otorite gücünden bağımsız hareket etmesi piyasalarda yer alan verilerdeki volatilite hareketlerinden etkilenmemekte ve bu özelliğinden dolayı volatilite hareketinin yüksek olduğu gelişmekte olan ülkelerde bir hedge enstrümanı olarak düşünülebilir hale gelmektedir.

Çalışma sonucunda Bitcoin'nin hiçbir yatırım aracı ile uzun vadeli olarak bir ilişki bulunmamasına rağmen hala piyasada bir alternatif bir yatırım arac1, para ya da emtia olarak değerlendirilip değerlendirilemeyeceği hususu güncelliğini korumaktadır. Çünkü bitcoin'nin mikro açıdan taşıdığı risklerine rağmen her ne kadar diğer yatırım araçlarıyla ilişkisi olmadığı gibi gözükse de aslında makro açıdan portföy çeşitlendirme prensibi açısından portföy riskini düşürebileceği ve portföy çeşitlendirme aracı olarak düşünülebilir. Piyasalarda son zamanlarda yaşanan volatilite hareketlerine baktığımızda bitcoin'nin diğer geleneksel yatırım araçlarına göre işlem hacminin düşük kalması, bitcoin'nin diğer geleneksel yatırım araçları ile ilgili ilişkinin olmadığını ortaya çıkaran bir unsur olarak değerlendirebilmek mümkündür. Gelecekte kripto paraların finansal sistemin değişimini sağlayan kayda değer bir unsur olması muhtemeldir. Bunun yaşanıp yaşanmayacağı bilinmese de finansal özgürlük anlayışının ilham kaynağı bitcoin olmuştur

Çalışmada ARDL sınır testi yapılarak Bitcoin ve önde gelen yatırım araçları arasında uzun vadeli eş bütünleşme ilişkisinin görülmemesine rağmen Merkez bankacılığının ve senyoraj gelirlerinin geleceği, analitik bilançoda, enflasyon ve faizde kripto paranın yeri, E-Ticaretteki sanal kredi kartları ödeme hacmi ile kripto para hacmi arasındaki ilişki ve Bankacılıktaki EFT, akreditif, çek gibi ödeme enstrümanları yerine kripto para kullanımının değerlendirilmesi gibi bitcoin'nin yatırım boyutu, para arzı, ödeme sistemi ve E-Ticaret bakımından ele alınması ayrıca fayda sağlayacaktır.

\section{Kaynakça}

Ateş, B. A. (2016). Kripto Para Birimleri, Bitcoin ve Muhasebesi. Çankırı Karatekin Üniversitesi Sosyal Bilimler Enstitüsü Dergisi, 7(1), 349-366.

Atik, M., Köse, Y., Yılmaz, B., \& Sağlam, F. K. (2015). ripto Para: Bitcoin ve Döviz Kurları Üzerine Etkileri. Bartın Üniversitesi IİBF Dergisi, 6(11), 247-262.

Baek, C., \& Elbeck, M. (2014). Bitcoins as an Investment or Speculative Vehicle? A First Look. Applied Economics Letters, 22(1), 30-34.

Baur, D., \& Dimpfl, T. (2017, Haziran 25). Realized Bitcoin Volatility. https://papers.ssrn.com/. adresinden alınmıştır

Baur, D., Lee, A., \& Hong, K. (2017). Bitcoin: Medium of exchange or speculative assets? https://papers.ssrn.com/sol3/papers.cfm?abstract_id= 2561183. adresinden alınmıştır

Beninga, S. (2000). Financial Modeling Uses Excel (Second Edition b.). Massachusetts Institute of Technology.

Bouoiyour, J., Selmi, R., \& Tiwari, A. K. (2015). Is Bitcoin Business Income or Speculative Foolery? New Ideas through an Improved Frequency Domain Analysis. Annals of Financial Economics, 10(01), 1-23.

Bouri, E., Jalkh, N., Molnár, P., \& Roubaud, D. (2017). Bitcoin for Energy Commodities Before and After the December 2013 Crash: Diversifier, Hedge or Safe Haven? Applied Economics, 5063-5073.

Carpenter, A. (2016). Portfolio diversification with Bitcoin. Journal of Undergraduate in France, 1-27.

Cheung, A. R. (2015). Crypto-Currency Bubbles: An Application of the Phillips-Shi-Yu (2013) Methodology on Mt. Gox Bitcoin Prices. Applied Economics, 47(23), 2348-2358.

Dwyer, G. (2015). The Economics of Bitcoin and Similar Private Digital Currencies. Journal of Financial Stability, 81-91.

Dyhrberg, A. H. (2015). Hedging Capabilities of Bitcoin. Is it the Virtual Gold? Finance Research Letters, , 139144.

Eswara, M. (2017). Cryptocurrency Gyration and Bitcoin Volatility. International Journal of Business and Administration Research Review, 3(18), 187-195.

Glaser, F., Zimmermann, K., Haferkorn, M., Weber, M., \& Siering, M. (2014). Bitcoin- Asset or Currency? Revealing Users'Hidden Intentions. Twenty Second 
European Conference on Information Systems., (s. 114). Tel Aviv.

Gujarati, D. (1999). Temel Ekonometri (Çev. Ü. Şenesen ve G.G. Şenesen), Literatür Yayınlarl, Istanbul.Temel Ekonometri (Çev. Ü. Şenesen ve G.G. Şenesen). İstanbul.: iteratür Yayınları, .

Gujarati, D. N. (2004). Economics Basic Econometrics,. Mcgraw Hill.

Hileman, G., \& Rauchs, M. (2017). Global Cryptocurrency Benchmarking Study. The Judge Business School at Cambridge University \& VISA, 25.

Jin Lim, S., \& Masih, M. (2017). Exploring Portfolio Diversification Opportunities in Islamic capital markets through Bitcoin: Evidence from MGARCHDCC and Wavelet Approaches.

Johansen, S., \& Juselius, K. (1990). Maximum Likelihood Estimation and Inference on Cointegration-with Application to the Demand for Money. Oxford Bulletin of Economics and Statistics, 169-210.

Koçoğlu, Ş., Çevik, Y. E., \& Tanrı̈ven, C. (2016). Bitcoin Piyasalarının Etkinliği, Likiditesi ve Oynaklığı. İşletme Araştırmaları Dergisi, 8(2), 77-97.

Kristoufek, L. (2015). What Are the Main Drivers of the Bitcoin Price? Evidence from Wavelet Coherence Analysis. PloS ONE, 10(4), 1-15.
Krugman, P., \& Wells, R. (2013). Makro İktisat. (Ç. F. kinci Baskıdan Çeviri, K. A. M.Murat Arslan, \& K. Göksal, Dü) Ankara: Palme Yayıncılı.

Moro, A., \& Kajtazi, A. (2017). Bitcoin, Portfolio Diversification and Chinese Financial Markets. SSRN Electronic Journal.

Nadarajah, S., \& Chu, J. (2017). On the inefficiency of Bitcoin. Economics Letters, 6-9.

Nakamoto, S. (2008, Haziran 25.06.2018). Bitcoin: A Peer to Peer Electronic Cash System. https://bitcoin.org/bitcoin.pdf: https://bitcoin.org/bitcoin.pdf adresinden alınmıştır

Öz, E. (2011). Ödeme Sistemlerinde Merkez Bankalarının Rolü ve Türkiye Örneği. İstanbul:: İstanbul Ticaret Üniversitesi SBE Yüksek Lisans Tezi.

Parası, İ. (2000). Parabanka ve Finansal Piyasalar. Bursa: Ezgi Kitapevi.

Plassaras, N. (2013). Regulating Digital Currencies: Bringing Bitcoin within the Reach of the IMF. Chicago Journal of International Law, 14(1), 376407.

Yermack, D. (2013). Is Bitcoin a Real Currency? NBER Working Paper No. 19747, National Bureau of Economic Research, 1-12. 